\title{
Prevalence and risk factors for reduced pulmonary function in diabetic patients: The Korea National Health and Nutrition Examination Survey
}

Hee Yeon Kim, Tae Seo Sohn, Hannah Seok, Chang Dong Yeo, Young Soo Kim, Jae Yen Song, Young Bok Lee, Dong-Hee Lee, Jae-Im Lee, Tae-Kyu Lee, Seong Cheol Jeong, Mihee Hong, and Hiun Suk Chae

Epidemiology Study Cluster of Uijeongbu St. Mary's Hospital, College of Medicine, Uijeongbu St. Mary's Hospital, The Catholic University of Korea, Seoul, Korea

Received: February 15, 2016 Revised : April 11, 2016 Accepted: May 3, 2016

\section{Correspondence to}

Tae Seo Sohn, M.D.

Department of Internal

Medicine, College of Medicine,

Uijeongbu St. Mary's Hospital,

The Catholic University of Korea,

271 Cheonbo-ro, Uijeongbu 11765 ,

Korea

Tel: $+82-31-820-3652$

Fax: +82-31-847-2719

E-mail: imsts@catholic.ac.kr
Background/Aims: An association between reduced pulmonary function and diabetes has been observed. Our aim was to evaluate the prevalence and risk factors associated with reduced pulmonary function in diabetic patients.

Methods: We analyzed data from the Korea National Health and Nutrition Examination Survey 2011 to 2013 . The study population included data from 8,784 participants (including 1,431 diabetics) aged $\geq 40$ years. Reduced pulmonary function was defined as patients with restrictive (forced expiratory volume in 1 second/ forced vital capacity $\left[\mathrm{FEV}_{1} / \mathrm{FVC}\right] \geq 0.7$ and $\mathrm{FVC}<80 \%$ of predicted value) or obstructive $\left(\mathrm{FEV}_{1} / \mathrm{FVC}<0.7\right)$ patterns.

Results: Subjects with diabetes had a higher prevalence of restrictive $(18.4 \%$ vs. $9.4 \%, p<0.001)$ and obstructive impairments (20\% vs. $12.6 \%, p<0.001)$ than those without diabetes. The adjusted odds ratios (aORs) (95\% confidence interval [CI]) for obstructive and restrictive pulmonary impairment were 0.91 ( 0.75 to 1.11) and 1.57 (1.30 to 1.89), respectively. In the diabetes population, age (aOR, 1.04; 95\% CI, 1.02 to 1.06 ), male sex (aOR, 1.40; 95\% CI, 1.04 to 1.88), and body mass index (aOR, 1.15; $95 \% \mathrm{CI}, 1.10$ to 1.21 ) were independently associated with restrictive pulmonary impairment. Age (aOR, 1.12; 95\% CI, 1.09 to 1.14), male sex (aOR, 4.24; 95\% CI, 2.42 to 7.44 ), and smoking at any point (ever-smoker: aOR, 1.96; 95\% CI, 1.16 to 3.33) were independent risk factors for obstructive pulmonary impairment in diabetics. Diabetes duration or glycated hemoglobin had no association with pulmonary impairment in diabetes.

Conclusions: Subjects with diabetes had a higher risk of restrictive pulmonary impairment than those without diabetes after adjusting for confounding factors. Older age, male sex, body mass index, and smoking were associated with reduced lung function in diabetes.

Keywords: Diabetes; Prevalence; Respiratory function tests; Risk factors

\section{INTRODUCTION}

The rise of a Westernized lifestyle and an increasing prevalence of obesity in Korea has contributed to the growing prevalence of diabetes $(12.4 \%$ of adults over 30 years old) and prediabetes (38.3\%) [1]. In subjects with diabetes, only $45.6 \%$ of diabetics reach glycemic control (glycated hemoglobin $[\mathrm{HbAic}]<7 \%$ ) [2], whereas half of 
the subjects with diabetes are consistently hyperglycemic, leading to an increased risk of developing complications and ultimately elevated morbidity and mortality $[3,4]$. Reduced pulmonary function in patients with diabetes has been observed in both cross-sectional and prospective studies [3-6]. Systematic review and meta-analysis of pulmonary function in diabetics supports the observation that diabetes is associated with a modest reduction in the forced expiratory volume in 1 second $\left(\mathrm{FEV}_{1}\right)$ as well as in the forced vital capacity (FVC) $[7,8]$. Therefore, decreased pulmonary function has been suggested as a potential complication of diabetes. Microangiopathy, systemic low-grade inflammation, autonomic neuropathy, and diminished respiratory muscle function have been proposed as possible causes of decreased pulmonary function in diabetics [7].

In addition to the rise in diabetes cases, the prevalence of chronic obstructive pulmonary disease (COPD) in Korea has increased from $7.8 \%$ to $12.9 \%$ in the past 10 years; most subjects with COPD were undiagnosed and untreated $[9,10]$. A recent general population-based study reported that $11.3 \%$ of subjects aged $\geq 40$ years had spirometrically-defined restrictive ventilator defects [11]. However, the prevalence of obstructive or restrictive pulmonary dysfunctions in diabetics has not yet been reported. Moreover, the risk factors associated with lung impairments in diabetes remain elusive.

In the present study, we investigated the prevalence of reduced pulmonary function and evaluated its associated risk factors in subjects with diabetes from a nationwide representative Korean population aged $\geq 40$ years.

\section{METHODS}

\section{Study population}

The Korea National Health and Nutrition Examination Survey (KNHANES) is a cross-sectional and nationally representative survey of the health and nutritional status of the Korean population by the Korean Centers for Disease Control and Prevention. A stratified multistage clustered probability sampling design was used to select a representative sample of civilian, non-institutionalized Korean adults at least 18 years of age. This survey consisted of a questionnaire about medical history and health-related lifestyle choices, anthropometric mea- surements, a physical examination, and biochemical laboratory measurements. For biochemical measurements, participants underwent blood sampling after 8 hours of overnight fasting. Pulmonary function test (PFT) was performed in subjects older than 40 years. For this study, we used data obtained during the 2011 to 2013 KNHANES. We excluded participants among the 24,594 sample individuals as follow: age < 40 years $(n=11,273)$, no available PFT data $(\mathrm{n}=3,985)$, unacceptable spirometry performance $(\mathrm{n}=379)$, or a history of malignancy $(\mathrm{n}=$ 173). Finally, a total of 8,784 participants (including 1,431 diabetics) were included in the analysis of the reduced pulmonary function in diabetes. This survey protocol was approved by the Institutional Review Board of the Korean Centers for Disease Control and Prevention.

\section{Pulmonary function test}

Spirometry was conducted by specially trained technicians using a dry rolling seal spirometer (2130 Spirometer, Sensor Medics, Yorba Linda, CA, USA). Measurement of $\mathrm{FEV}_{1}$ and FVC were conducted in accordance with guidelines from the American Thoracic Society [12]. Spirometry was repeated at least three times to ensure reproducibility and validity. Values used in the study were $\mathrm{FEV}_{1}, \mathrm{FVC}$, and $\mathrm{FEV}$, to FVC ratio $\left(\mathrm{FEV}_{1} /\right.$ FVC). Predicted spirometry values were calculated from the Korean reference equations, based on representative samples of the Korean population [13].

\section{Definitions}

Obstructive impairment was defined as $\mathrm{FEV}_{1} / \mathrm{FVC}<$ 0.70. Restrictive impairment was defined as $\mathrm{FEV}_{1} / \mathrm{FVC}$ $\geq 0.70$ and $\mathrm{FVC}<80 \%$ predicted. Normal lung function was defined as $\mathrm{FEV}_{1} / \mathrm{FVC} \geq 0.70$ and $\mathrm{FVC} \geq 80 \%[14,15]$. Diabetes was defined as fasting plasma glucose levels $\geq$ $126 \mathrm{mg} / \mathrm{dL}$ ( $\geq 7.0 \mathrm{mmol} / \mathrm{L}$ ), HbAic $\geq 6.5 \%$ or treatment with antidiabetes medications or previous diagnosis of diabetes by a doctor.

\section{Statistical analyses}

Data are expressed as means or percentages with standard errors. Clinical characteristics were compared according to presence of diabetes using the Student $t$ test for continuous variables and the chi-square test for categorical variables. Differences among groups based on spirometry were compared by analysis of variance for 
Table 1. Clinical characteristics of the study population

\begin{tabular}{|c|c|c|c|}
\hline Characteristic & Diabetics $(\mathrm{n}=1,431)$ & Non-diabetics $(\mathrm{n}=7,353)$ & $p$ value \\
\hline Age, yr & $59.1 \pm 0.3$ & $53 \cdot 3 \pm 0.2$ & $<0.001$ \\
\hline Male sex, \% & $56.9(1.6)$ & $48.9(0.6)$ & $<0.001$ \\
\hline Body mass index, $\mathrm{kg} / \mathrm{m}^{2}$ & $25 \cdot 4 \pm 0.1$ & $24.2 \pm 0$ & $<0.001$ \\
\hline Waist circumference, $\mathrm{cm}$ & $87.5 \pm 0.3$ & $82.4 \pm 0.2$ & $<0.001$ \\
\hline Smoker, \% & & & 0.026 \\
\hline Non-smoker & $17(0.6)$ & $65.2(0.8)$ & \\
\hline Ex-smoker & $60.1(1.8)$ & $17.8(0.7)$ & \\
\hline Current-smoker & $20(1.4)$ & $19.9(1.5)$ & \\
\hline Heavy drinker, \% & $20.1(1.3)$ & $19(0.6)$ & 0.426 \\
\hline Regular exercise, \% & $15.9(1.2)$ & $19.2(0.6)$ & 0.021 \\
\hline Hypertension, \% & $55.6(1.7)$ & $32.5(0.7)$ & $<0.001$ \\
\hline Antidyslipidemia drug, \% & $18.4(1.1)$ & $5.5(0.3)$ & $<0.001$ \\
\hline Diabetes duration, yr & $4.7 \pm 0.22$ & $0.003 \pm 0.002$ & $<0.001$ \\
\hline Fasting plasma glucose, mg/dL & $135.8 \pm 1.2$ & $95 \pm 0.2$ & $<0.001$ \\
\hline HbAic, \% & $7.3 \pm 0.004$ & $5.6 \pm 0.01$ & $<0.001$ \\
\hline Total cholesterol, mg/dL & $190.1 \pm 1.5$ & $195.8 \pm 0.5$ & $<0.001$ \\
\hline Triglyceride, mg/dL & $156.7(150.2-163.5)$ & $119.6(117.5-121.8)$ & $<0.001$ \\
\hline HDL-C, mg/dL & $46.5 \pm 0.3$ & $51.7 \pm 0.2$ & $<0.001$ \\
\hline LDL-C, mg/dL & $108.1 \pm 1.3$ & $116.8 \pm 0.4$ & $<0.001$ \\
\hline $\mathrm{FEV}_{1} \%$ predicted & $89 \cdot 3 \pm 0.4$ & $92.4 \pm 0.2$ & $<0.001$ \\
\hline FVC \% predicted & $89.2 \pm 0.4$ & $93.9 \pm 0.2$ & $<0.001$ \\
\hline $\mathrm{FEV}_{1} / \mathrm{FVC}$ & $0.8 \pm 0.002$ & $0.8 \pm 0.001$ & $<0.001$ \\
\hline \multicolumn{4}{|l|}{ Spirometry, \% } \\
\hline Restrictive & $18.4(1.4)$ & $9.4(0.5)$ & $<0.001$ \\
\hline Obstructive & $20(1.4)$ & $12.6(0.5)$ & $<0.001$ \\
\hline Restrictive or obstructive & $32.2(1.5)$ & $19.8(0.6)$ & $<0.001$ \\
\hline
\end{tabular}

Values are presented as mean $\pm \mathrm{SE}$, percentage $(\mathrm{SE})$, or geometric mean (95\% confidence interval).

HbA1c, glycated hemoglobin; HDL-C, high density lipoprotein cholesterol; LDL-C, low density lipoprotein cholesterol; FEV ${ }_{1}$, forced expiratory volume in 1 second; FVC, forced vital capacity.

continuous variables and the chi-square test for categorical variables. The odds ratio (OR) and $95 \%$ confidence interval (95\% CI) for factors associated with obstructive or restrictive pulmonary impairment were analyzed using multivariate logistic regression analysis. $p$ values < 0.05 were considered statistically significant. SAS version 9.3 software (SAS Inc., Cary, NC, USA) for Windows was used for our analyses.

\section{RESULTS}

\section{Clinical characteristics of the study population}

The characteristics of the 8,784 eligible subjects stratified by the presence of diabetes are summarized in Table 1. Age, body mass index (BMI), waist circumference, the proportion of subjects who are currently or are ex-smokers (ever-smokers), had hypertension, or were taking antidyslipidemia medications were higher in those with diabetes than in those without diabetes. Subjects with diabetes had a higher prevalence of restrictive 
Table 2. Clinical characteristics of the diabetic study population according to pulmonary function

\begin{tabular}{|c|c|c|c|c|}
\hline Characteristic & $\operatorname{Normal}(n=941)$ & Restrictive $(\mathrm{n}=235)$ & Obstructive $(\mathrm{n}=255)$ & $p$ value \\
\hline Age, yr & $57.1 \pm 0.4$ & $60.6 \pm 0.7^{\mathrm{a}}$ & $65.6 \pm 0.7^{a}$ & $<0.001$ \\
\hline Male sex, \% & $53(2)$ & $52.5(3.9)$ & $76.5(3.1)^{\mathrm{a}}$ & $<0.001$ \\
\hline Body mass index, kg/m² & $25 \cdot 3 \pm 0.1$ & $26.6 \pm 0.3^{\mathrm{a}}$ & $24.5 \pm 0.2^{\mathrm{a}}$ & $<0.001$ \\
\hline Waist circumference, $\mathrm{cm}$ & $86.9 \pm 0.3$ & $90 \pm 0.7^{\mathrm{a}}$ & $87.7 \pm 0.7$ & $<0.001$ \\
\hline Smoker, \% & & & & $<0.001$ \\
\hline Non-smoker & $64.9(2.2)$ & $60.8(4.2)$ & $37.7(4.2)^{\mathrm{a}}$ & \\
\hline Ex-smoker & $16.4(1.7)$ & $18.5(3.4)$ & $37 \cdot 5(4 \cdot 4)$ & \\
\hline Current-smoker & $18.7(1.9)$ & $20.7(4.1)$ & $24.8(4.1)$ & \\
\hline Heavy drinker, \% & $19.6(1.7)$ & $20.6(3.7)$ & $21.7(3.1)$ & 0.845 \\
\hline Regular exercise, \% & $16.7(1.5)$ & $18.3(3)$ & $10.7(2)$ & 0.070 \\
\hline Hypertension, \% & $52.5(2.1)$ & $60.7(3.9)$ & $63(3.7)^{\mathrm{a}}$ & 0.019 \\
\hline Antidyslipidemia drug, \% & $17.9(1.4)$ & $23.7(2.9)$ & $16(2.6)$ & 0.110 \\
\hline Diabetes duration, yr & $4.5 \pm 0.3$ & $4.6 \pm 0.5$ & $5.9 \pm 0.5$ & 0.060 \\
\hline Fasting plasma glucose, mg/dL & $138 \pm 1.6$ & $133.9 \pm 2.8$ & $129.1 \pm 2.2^{\mathrm{a}}$ & 0.009 \\
\hline $\mathrm{HbAic}, \%$ & $7 \cdot 3 \pm 0.1$ & $7 \cdot 3 \pm 0.1$ & $7.1 \pm 0.1^{\mathrm{a}}$ & 0.028 \\
\hline Total cholesterol, mg/dL & $192 \pm 1.9$ & $187 \cdot 6 \pm 3 \cdot 3$ & $184 \cdot 7 \pm 3 \cdot 4$ & 0.134 \\
\hline Triglyceride, mg/dL & $156.1(148.1-164.5)$ & $159.3(143.8-176.5)$ & $156.7(141.9-173)$ & 0.943 \\
\hline HDL-C, mg/dL & $46.8 \pm 0.4$ & $46.1 \pm 0.7$ & $45 \cdot 9 \pm 0.9$ & 0.544 \\
\hline LDL-C, mg/dL & $110.3 \pm 1.6$ & $104 \cdot 3 \pm 3$ & $102.2 \pm 2.7^{\mathrm{a}}$ & 0.017 \\
\hline $\mathrm{FEV}_{1} \%$ predicted & $95.1 \pm 0.4$ & $78.1 \pm 0.6^{\mathrm{a}}$ & $76.1 \pm 1.2^{\mathrm{a}}$ & $<0.001$ \\
\hline FVC \% predicted & $93.2 \pm 0.3$ & $74.0 \pm 0.4^{\mathrm{a}}$ & $86.9 \pm 1.0^{\mathrm{a}}$ & $<0.001$ \\
\hline $\mathrm{FEV}_{1} / \mathrm{FVC}$ & $0.8 \pm 0.002$ & $0.8 \pm 0.004$ & $0.6 \pm 0.005^{\mathrm{a}}$ & $<0.001$ \\
\hline
\end{tabular}

Values are presented as mean $\pm \mathrm{SE}$, percentage $(\mathrm{SE})$, or geometric mean (95\% confidence interval).

HbA1c, glycated hemoglobin; HDL-C, high density lipoprotein cholesterol; LDL-C, low density lipoprotein cholesterol; FEV forced expiratory volume in 1 second; FVC, forced vital capacity.

${ }^{a} p<0.05$ compared to subjects with normal lung function.

(18.4\% vs. $9.4 \%, p<0.001)$ and obstructive impairments (20\% vs. $12.6 \%, p<0.001$ ) than those without diabetes. However, subjects with diabetes were older, predominantly male, with higher BMI and a greater waist circumference, and ever-smokers compared to subjects without diabetes. The ORs (95\% CI) adjusted for age, sex, BMI, waist circumference, and ever-smoker of diabetes for obstructive and restrictive pulmonary impairment were 0.91 ( 0.75 to 1.11 ) and 1.57 (1.30 to 1.89 ), respectively.

\section{Clinical characteristics of the diabetes population according to pulmonary function}

Among subjects with diabetes $(n=1,431)$, those with restrictive pulmonary impairment were more likely to be of older age with higher BMI and a greater waist circumference compared to subjects with normal pulmonary function (Table 2). Subjects with obstructive pulmonary impairment were more likely to be older, with lower BMI, ever-smokers, and have lower fasting plasma glucose levels, lower HbArc, and lower low density lipoprotein cholesterol levels compared to subjects with normal pulmonary function.

\section{Factors influencing restrictive and obstructive pul-} monary impairment among the diabetes population A multivariable logistic regression model for factors associated with restrictive and obstructive pulmonary impairment is shown in Table 3. Subjects who were older (adjusted OR, 1.04; 95\% CI, 1.02 to 1.06), male (adjusted OR, 1.40; 95\% CI, 1.04 to 1.88) and who had higher BMI (adjusted OR, 1.15; 95\% CI, 1.10 to 1.20) had increased ORs for restrictive pulmonary impairment, whereas 


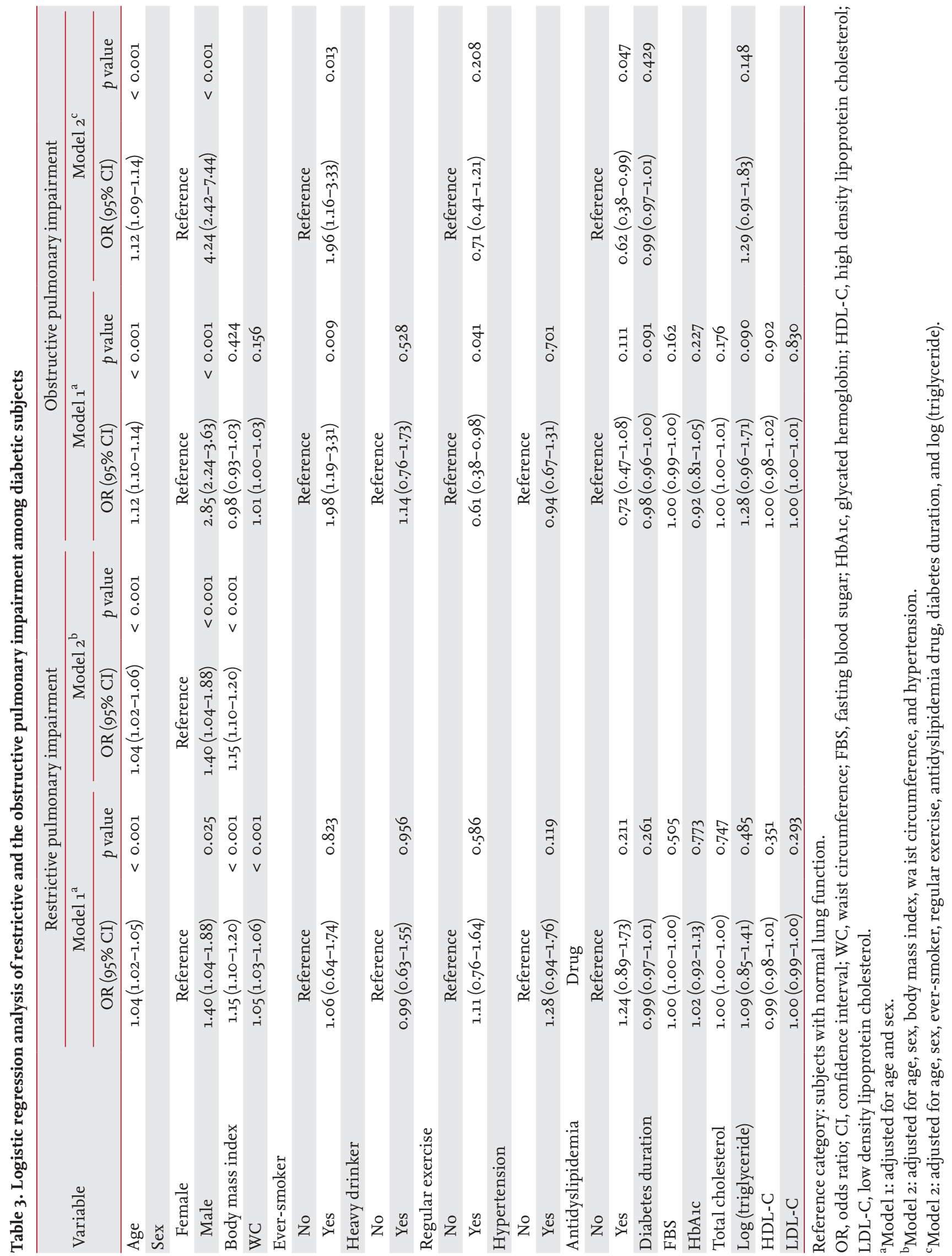


older age (adjusted OR, 1.12; 95\% CI, 1.09 to 1.14), male sex (adjusted OR, 4.24; 95\% CI, 2.42 to 7.44), and ever-smokers (adjusted OR, 1.96; 95\% CI, 1.16 to 3.33) were independently associated with obstructive pulmonary impairment. There was no association between diabetes duration or HbA1c and pulmonary impairment in participants with diabetes.

\section{DISCUSSION}

In this study, we examined the prevalence and risk factors for obstructive and restrictive pulmonary impairments in diabetics using a nationally representative sample of the Korea population. Weighted prevalence of obstructive and restrictive pulmonary impairment were $20 \%$ and $18.4 \%$, respectively, in diabetic subjects aged $\geq 40$ years. Older age, male sex, and increasing BMI were independently associated with restrictive pulmonary impairment. Older age, male sex, and ever-smoking were statistically significant variables for obstructive pulmonary impairment.

Previous epidemiologic studies have reported a prevalence of restrictive pulmonary impairment in $7 \%$ to $13 \%$ of adults $[16,17]$. The prevalence of restrictive lung disease was $11.3 \%$ in a recent general population-based study using the KNHANES [11]. In our analysis, restrictive pulmonary impairments were present in subjects with or without diabetes at $18.4 \%$ and $9.4 \%$, respectively. Diabetes was independently associated with restrictive pulmonary impairment adjusted for age, sex, BMI, waist circumference, and ever-smoker (adjusted OR, 1.57; 95\% CI, 1.30 to 1.89). Previous studies suggesting an association between diabetes and restrictive pulmonary dysfunction [4,18-20] support a high prevalence of restrictive pulmonary impairment among the diabetic population. The prevalence of obstructive lung disease was reported to be $12.9 \%$ in Korea [10]. Although less consistent association of diabetes with reduction in $\mathrm{FEV}_{1}$ than FVC, adults with diabetes have lower FEV compared to non-diabetic subjects [7]. In our analysis, obstructive pulmonary impairment was present in $20 \%$ and $12.6 \%$ in subjects with or without diabetes, respectively. However, subjects with diabetes were older, predominantly male, with higher BMI and a greater waist circumference, and ever-smokers compared to subjects without diabetes in our KNHANES data. Diabetes was not a significant risk factor for obstructive pulmonary impairment after adjusting for age, sex, BMI, waist circumference, and ever-smoker (adjusted OR, 0.91; 95\% CI, 0.75 to 1.11). Further analysis is needed to determine diabetes is an independent risk factor for obstructive pulmonary impairment.

To our knowledge, few studies have investigated the risk factors for reduced pulmonary function in diabetics. Our study showed that aging was independently associated with reduced pulmonary function in diabetics. $\mathrm{FEV}_{1}$ and FVC gradually decrease with age. Due to the greater decline in $\mathrm{FEV}_{1}$, the $\mathrm{FEV}_{1} / \mathrm{FVC}$ ratio also decreases with age [21]. We also determined that male sex was associated with reduced pulmonary function. This may be partly explained by the greater fat deposits in the abdominal region of men in contrast with the greater gynoid fat presence in women. The excess adiposity encasing the thorax and the abdomen disturbs the respiratory muscles, especially in men [22]. Our study also showed that BMI was significantly related to restrictive pulmonary impairment. This result was in line with previous studies reporting an association between restrictive pulmonary impairment and obesity [23,24]. The accumulation of fat may affect lung and chest wall compliance, causing a stiffening of the total respiratory system [23]. Cigarette smoking was a risk factor for obstructive pulmonary impairment in this study. The effect of cigarette smoking on $\mathrm{FEV}_{1}$ decline has been documented previously $[25,26]$.

It has been suggested that the reduced pulmonary function in diabetics is associated with diabetes duration as well as HbA1c $[3,4]$. However, neither diabetes duration nor $\mathrm{HbA1c}$ was a significant factor for reduced pulmonary function in this study; this may be partly explained by the relatively short duration of diabetes (4.7 \pm 0.22 years) and good glycemic control (HbAic, 7.3\% $\pm 0.004 \%)$. Moreover, the HbAlc level at one particular time does not reflect lifetime glycemic control.

This study had several limitations. First, due to the cross-sectional design, a causal relationship between decreased lung function and risk factors in diabetes could not be determined. Second, due to the lack of data on the measurement of total lung capacity, restrictive pulmonary impairment was defined by a low FVC along with a normal or high $\mathrm{FEV}_{1} / \mathrm{FVC}$ ratio. However, any 
misclassification of pulmonary impairment may have biased toward no association, and underestimating the effect. Despite these limitations, this study makes some important contributions. The risk factors for reduced pulmonary function in diabetes pose great implications. Although the decreased lung function caused by diabetes has minimal effects on the pulmonary reserve capacity, overlapping conditions such as age, obesity, male sex, or smoking, may have synergistic effects on the loss of lung function.

In summary, subjects with diabetes had a higher risk of restrictive pulmonary impairment than those without diabetes after adjusting for confounding factors. Older age, male sex, BMI, and smoking were all independently associated with reduced lung function in diabetics.

\section{KEY MESSAGE}

1. Older age, male sex, and higher body mass index were independent risk factors for restrictive pulmonary impairment.

2. Older age, male sex, and ever-smokers were independently associated with obstructive pulmonary impairment.

\section{Conflict of interest}

No potential conflict of interest relevant to this article was reported.

\section{REFERENCES}

1. Jeon JY, Ko SH, Kwon HS, et al. Prevalence of diabetes and prediabetes according to fasting plasma glucose and HbA1c. Diabetes Metab J 2013;37:349-357.

2. Jeon JY, Kim DJ, Ko SH, et al. Current status of glycemic control of patients with diabetes in Korea: the fifth Korea National Health and Nutrition Examination Survey. Diabetes Metab J 2014;38:197-203.

3. Davis TM, Knuiman M, Kendall P, Vu H, Davis WA. Reduced pulmonary function and its associations in type 2 diabetes: the Fremantle Diabetes Study. Diabetes Res Clin Pract 2000;50:153-159.

4. Yeh HC, Punjabi NM, Wang NY, et al. Cross-sectional and prospective study of lung function in adults with type 2 diabetes: the Atherosclerosis Risk in Communities (ARIC) study. Diabetes Care 2008;31:741-746.

5. Lange P, Parner J, Schnohr P, Jensen G. Copenhagen City Heart Study: longitudinal analysis of ventilatory capacity in diabetic and nondiabetic adults. Eur Respir J 2002;20:1406-1412.

6. Litonjua AA, Lazarus R, Sparrow D, Demolles D, Weiss ST. Lung function in type 2 diabetes: the Normative Aging Study. Respir Med 2005;99:1583-1590.

7. Klein OL, Krishnan JA, Glick S, Smith LJ. Systematic review of the association between lung function and type 2 diabetes mellitus. Diabet Med 2010;27:977-987.

8. van den Borst B, Gosker HR, Zeegers MP, Schols AM. Pulmonary function in diabetes: a metaanalysis. Chest 2010;138:393-406.

9. Kim DS, Kim YS, Jung KS, et al. Prevalence of chronic obstructive pulmonary disease in Korea: a population-based spirometry survey. Am J Respir Crit Care Med 2005;172:842847.

10. Hwang YI, Yoo KH, Sheen SS, et al. Prevalence of chronic obstructive pulmonary disease in Korea: the result of forth Korean National Health and Nutrition Examination Survey. Tuberc Respir Dis 2011;71:328-334.

11. Lee JY, Hwang YI, Park YB, et al. Prevalence of spirometrically-defined restrictive ventilatory defect in Korea: the fourth-2, 3, and fifth Korean National Health and Nutrition Examination Survey, 2008-2012. J Korean Med Sci 2015;30:725-732.

12. American Thoracic Society. Standardization of spirometry, 1994 update. Am J Respir Crit Care Med 1995;152:11071136.

13. Choi JK, Paek D, Lee JO. Normal predictive values of spirometry in Korean population. Tuberc Respir Dis 2005;58:230-242.

14. Evans SE, Scanlon PD. Current practice in pulmonary function testing. Mayo Clin Proc 2003;78:758-763.

15. Mannino DM, Ford ES, Redd SC. Obstructive and restrictive lung disease and markers of inflammation: data from the Third National Health and Nutrition Examination. Am J Med 2003;114:758-762.

16. Mannino DM, Doherty DE, Sonia Buist A. Global Initiative on Obstructive Lung Disease (GOLD) classification of lung disease and mortality: findings from the Atherosclerosis Risk in Communities (ARIC) study. Respir Med 2006;100:115-122.

17. Mannino DM, Thorn D, Swensen A, Holguin F. Preva- 
lence and outcomes of diabetes, hypertension and cardiovascular disease in COPD. Eur Respir J 2008;32:962969.

18. Kim HK, Kim CH, Jung YJ, et al. Association of restrictive ventilatory dysfunction with insulin resistance and type 2 diabetes in Koreans. Exp Clin Endocrinol Diabetes 2011;119:47-52.

19. Oda E, Kawai R. A cross-sectional relationship between vital capacity and metabolic syndrome and between vital capacity and diabetes in a sample Japanese population. Environ Health Prev Med 2009;14:284-291.

20. Walter RE, Beiser A, Givelber RJ, O'Connor GT, Gottlieb DJ. Association between glycemic state and lung function: the Framingham Heart Study. Am J Respir Crit Care Med 2003;167:911-916.

21. Sharma G, Goodwin J. Effect of aging on respiratory system physiology and immunology. Clin Interv Aging 2006;1:253-260.
22. Enzi G, Gasparo M, Biondetti PR, Fiore D, Semisa M, Zurlo F. Subcutaneous and visceral fat distribution according to sex, age, and overweight, evaluated by computed tomography. Am J Clin Nutr 1986;44:739-746.

23. Canoy D, Luben R, Welch A, et al. Abdominal obesity and respiratory function in men and women in the EPIC-Norfolk Study, United Kingdom. Am J Epidemiol 2004;159:1140-1149.

24. Melo LC, Silva MA, Calles AC. Obesity and lung function: a systematic review. Einstein (Sao Paulo) 2014;12:120-125.

25. Bano R, Ahmad N, Mahagaonkar AM, Latti RG. Study of lung functions in smokers and non-smokers in rural India. Indian J Physiol Pharmacol 2011;55:84-88.

26. Boskabady MH, Mahmoodinia M, Boskabady M, Heydari GR. Pulmonary function tests and respiratory symptoms among smokers in the city of Mashhad (north east of Iran). Rev Port Pneumol 2011;17:199-204. 